\title{
The effect of vibratory stress on the welding microstructure and residual stress distribution
}

\author{
A S M Y Munsi*, A J Waddell and C A Walker \\ Department of Mechanical Engineering, University of Strathclyde, Glasgow, Scotland, UK
}

\begin{abstract}
Previous studies have suggested that weld microstructure may be modified by the presence of static stresses. In this investigation, vibratory stress was applied to mild steel specimens while they were being welded to observe its effect on the residual stress, microstructure and hardness of the material. Residual stresses were found to decrease in response to vibration whether it was applied during welding or after welding. It was found that the applied stress influenced the grain growth process in the weld. As a result of the treatment the hardness of the material was found to be increased by 25 per cent.
\end{abstract}

Keywords: residual stress, vibratory stress relief, vibratory weld conditioning, microstructure, phase transformation

\section{INTRODUCTION}

Welding processes inevitably induce a state of residual stress into materials and products. This poses a series of problems, in terms of dimensional stability, corrosion cracking, reduced fatigue life and structural integrity. The conventional way to relieve the residual stresses is by post-weld heat treatment (PWHT), which is an effective process, but it suffers from several disadvantages: the cost of treatment in terms of equipment and energy is high; the growth of oxide scale on the surface implies the need for subsequent finishing processes to remove the scale; in many metals, annealing relieves residual stresses at the cost of important mechanical properties and, in some metals, PWHT is unable to relieve the residual stresses. The use of vibration to modify welding residual stress has been reported, but as yet the process has not received a detailed investigation.

The current study is part of a detailed investigation [1] that was aimed at finding out whether the vibratory method could be used systematically to relieve residual stresses in welded joints. Two forms of treatment have been investigated with vibratory stress relief (VSR): 'during-welding' treatment and 'post-weld' treatment. In the 'during-welding' treatments the specimens are welded while the specimens are being vibrated. On the

The MS was received on 15 March 2000 and was accepted after revision for publication on 19 January 2001.

*Corresponding author: Department of Mechanical Engineering, University of Strathclyde, James Weir Building, 75 Montrose Street, Glasgow G1 1XJ, Scotland, UK. other hand, in the 'post-weld' treatments the specimens are welded without any treatment, the specimens cool and then the vibratory treatments are carried out. The investigation reported here relates to both 'during-welding' and 'post-weld' treatments. In addition to the residual stress, this study investigated the effect of vibratory stress on the crystallographic orientation and change in the hardness of the weldments due to VSR treatment.

\section{BACKGROUND OF THIS RESEARCH}

Previous studies involving both 'during-welding' and 'post-weld' treatments have reported the effect of treatment on residual stresses. It would appear that the effect of vibration on welding microstructure has not been reported so far. Only one published paper [1] has been found that applied a rigid body motion vibration to the specimens and found an improvement in mechanical properties of the material. Munsi [2], Aoki and Nishimura [3], Aoki et al. [4], Maekawa et al. [5] and Nakagiri et al. [6] have investigated 'during-welding' treatments. The results of those investigations were mixed, in that some found a reduction in residual stresses and the others concluded with a negative comment. Bühler and Pfalzgraf [7], Shanker et al. [8], Sonsino et al. [9], Wozney and Crawmer [10], Houck [11], Botros [12], Rich [13] and Fenghua and Dexin [14] have all reported on 'post-weld' treatments. Bühler and Pfalzgraf [7] reported negative results. Houck [11] and Botros [12] reported a large degree of success in reducing residual stress from a high 
tensile value to an isotropic distribution of negative stress. Rich [13] was highly successful in reducing the residual stress from 200 to $38 \mathrm{MPa}$. Wozney and Crawmer [10] reported no change in residual stress as a result of vibratory treatment. Fenghua and Dexin [14] found a significant reduction in residual stress due to vibratory treatment, whereas artificial ageing showed a lower reduction than the VSR treatment. Sonsino [9] found a very small or negligible reduction in residual stress and commented that VSR could not replace heat treatment.

Bhadeshia [15] showed that, due to the presence of a uniaxial applied stress, the form of the transformation products of the weld (martensite, acicular ferrite, etc.) became anisotropic. Campbell [16] noticed that grain refinement occurred and the mechanical properties were improved in castings due to the application of vibration during casting.

It has been established that both 'during-welding' and 'post-weld' vibration treatments can reduce residual stresses [2-8, 11-14]. It has also been established that uniaxial stress causes a change [15] in the grain orientation, and vibratory stress causes grain refinement [16] in cast irons. From the above findings, it was postulated that, like uniaxial stress, vibratory stress would influence grain orientation during the process of cooling. It was assumed that there might be a relationship between the reduction in residual stresses and change in the grain orientation and grain refinement. This study was carried out to explore the relationship between the residual stresses, grain structures and change in hardness of the materials.

\section{TEST SPECIMENS AND MATERIAL PROPERTIES}

The specimens were made from cold-rolled mild steel flat bar of cross-section $6.35 \mathrm{~mm} \times 76.2 \mathrm{~mm}$. A metallographic study revealed that the bar was hot rolled and then cold rolled to obtain the surface finish and mechanical properties. The material specification of the flat bar was BS 970 080A15. Carbon and other alloying elements of the bar are shown in Table 1. The microstructure of the as-received flat bar is shown in Fig. 1.
Table 1 Alloying elements of the specimen

\begin{tabular}{lllll}
\hline $\mathrm{C}(\mathrm{wt} \%)$ & $\mathrm{Si}(\mathrm{wt} \%)$ & $\mathrm{Mn}(\mathrm{wt} \%)$ & $\mathrm{P}(\mathrm{wt} \%)$ & $\mathrm{S}(\mathrm{wt} \%)$ \\
\hline 0.18 & 0.23 & 0.88 & 0.013 & 0.011 \\
\hline
\end{tabular}

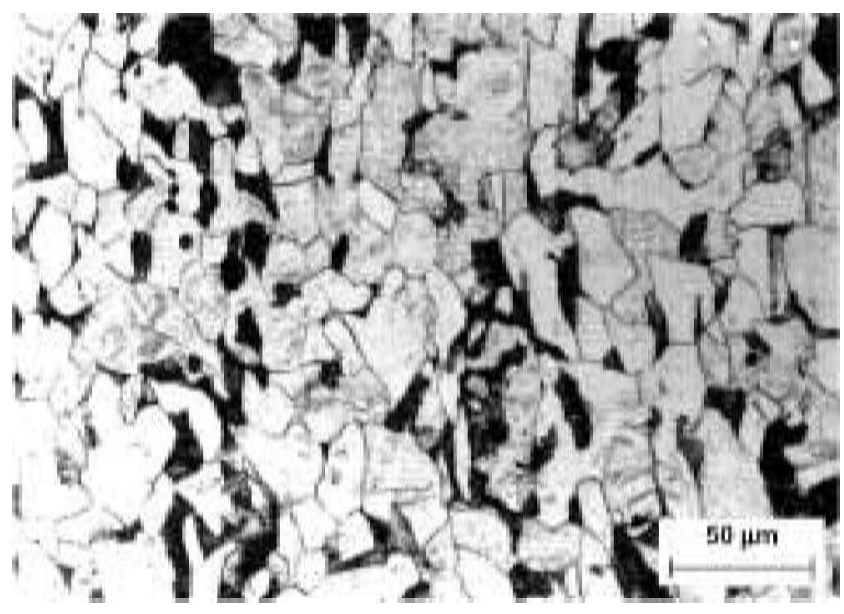

Fig. 1 Microstructure of the as-received flat bar

The total length of the specimen was $290 \mathrm{~mm}$, which included the clamping area and the free length for stress induction. It was decided to put a single-pass bead weld line near the clamp (Fig. 2) of the specimen to induce welding residual stresses. The specimen is shown in Fig. 2.

The ambient mechanical properties of the flat bar were determined by a tensile test where the properties were recorded as a 0.2 per cent offset yield stress of $607 \mathrm{MPa}$ and an ultimate tensile strength of $611 \mathrm{MPa}$. During welding, the weld and surrounding area were heated to about $1200^{\circ} \mathrm{C}$, and in consequence the yield stress was reduced to a very low value.

\section{EXPERIMENTAL PROCEDURE}

To carry out this investigation a line of bead-on-plate weld was applied to the specimen of Fig. 2. The

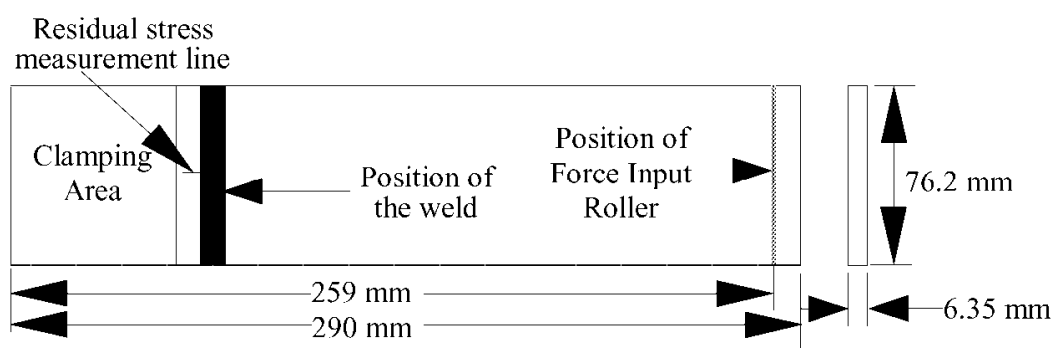

Fig. 2 Cantilever beam specimen 


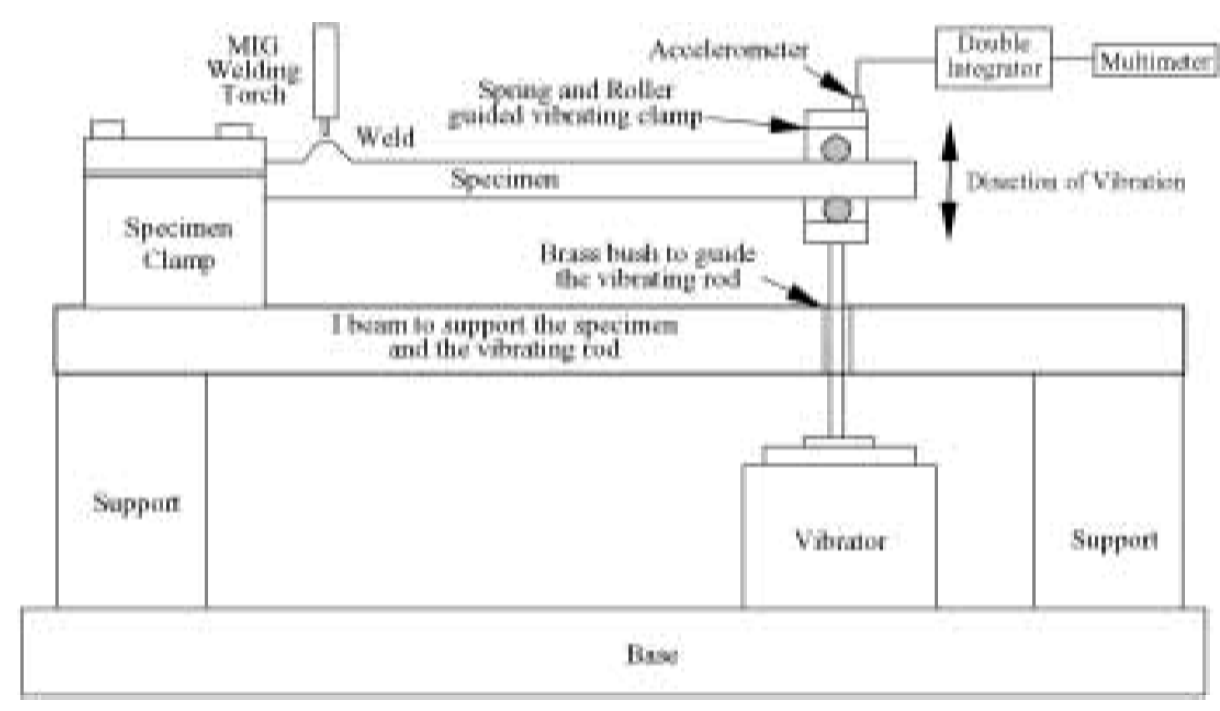

Fig. 3 Experimental set-up: flexural vibration treatment of the cantilever beam (MIG, metal inert gas)

experimental set-up for this investigation is shown in Fig. 3. Some specimens were welded without any treatment and some were vibrated applying different levels of vibratory amplitudes while they were being welded. The frequency of vibration was kept constant at $25 \mathrm{~Hz}$. In the 'during-welding' treatment the welding speed, heat input and time of vibration were kept constant, and the amplitude of vibration was varied in which the applied stress range was from \pm 48 to $\pm 288 \mathrm{MPa}$. Of the unvibrated specimens, some of them were kept as control specimens and some were 'post-weld' vibratory treated to relieve the residual stresses. In the 'post-weld' treatment the applied stress was kept constant to $\pm 300 \mathrm{MPa}$ and the time of vibration was varied. The residual stresses of the specimens were measured using an X-ray diffractometer. The residual stresses of the 'during-welding' treated specimens were compared with the residual stresses with the control specimens. In the 'post-weld' treated specimens, the specimens were vibrated in several steps and the change in the residual stresses due to treatments was investigated.

The specimens were cut, polished and etched for metallurgical investigation. In the etching process, 2 per cent Nital (2 parts nitric acid and 98 parts methanol) was used as the etching agent. A constant speed of welding (338 $\mathrm{mm} / \mathrm{min})$ was maintained using a stepper-motordriven welding torch carrier. The voltage and current in the welding process were $25 \mathrm{~V}$ and 195 A respectively. A second batch of specimens was processed at a higher level of heat input. The welding conditions of the two batches are shown in Table 2 .

The welding conditions of the second batch were changed to increase the heat input to the weld to increase the width of the heat-affected zone (HAZ) to facilitate a detailed investigation of the HAZ. It was observed that, in samples of low heat input, there was not any microstructural difference between vibrated and unvibrated samples. The details of the result are described in the experimental result section. The different zones of the weld are shown in the schematic diagram in Fig. 4. Investigation was carried out in the welds and in the HAZ (at the weld toe, and on the side of the specimen opposite the weld).

\section{APPLIED STRESS CALIBRATION}

The dynamically applied stress was calibrated using a P3500 digital strain indicator, an accelerometer, a double integrator and a multimeter. The calibration was carried out on the experimental set-up shown in Fig. 3. A strain gauge was fixed on the selected area (for residual stress measurement see Fig. 2) of the specimen to measure the applied stresses in the longitudinal directions. An accelerometer was attached to the vibrating roller clamp (Fig. 3). Vibration was applied to the clamp and the corresponding applied stress at the selected area was measured. The amplitude of vibration was varied and the corresponding applied stress was recorded. From the recorded data the applied stress was calculated in terms of displacement amplitude of the vibrating clamp. The calibration constant was found to be $1 \mathrm{~V}$ (r.m.s.) equal to 97.9 MPa.

It should be noted here that the above calibration would be directly valid for the 'post-weld' treatments as

Table 2 Welding conditions of the two batches of specimens

\begin{tabular}{llll}
\hline Voltage $(\mathrm{V})$ & Current $(\mathrm{A})$ & $\begin{array}{l}\text { Welding speed } \\
(\mathrm{mm} / \mathrm{min})\end{array}$ & Number of passes \\
\hline 25 & 195 & 338 & 1 \\
25.5 & 204 & 284 & 1 \\
\hline
\end{tabular}




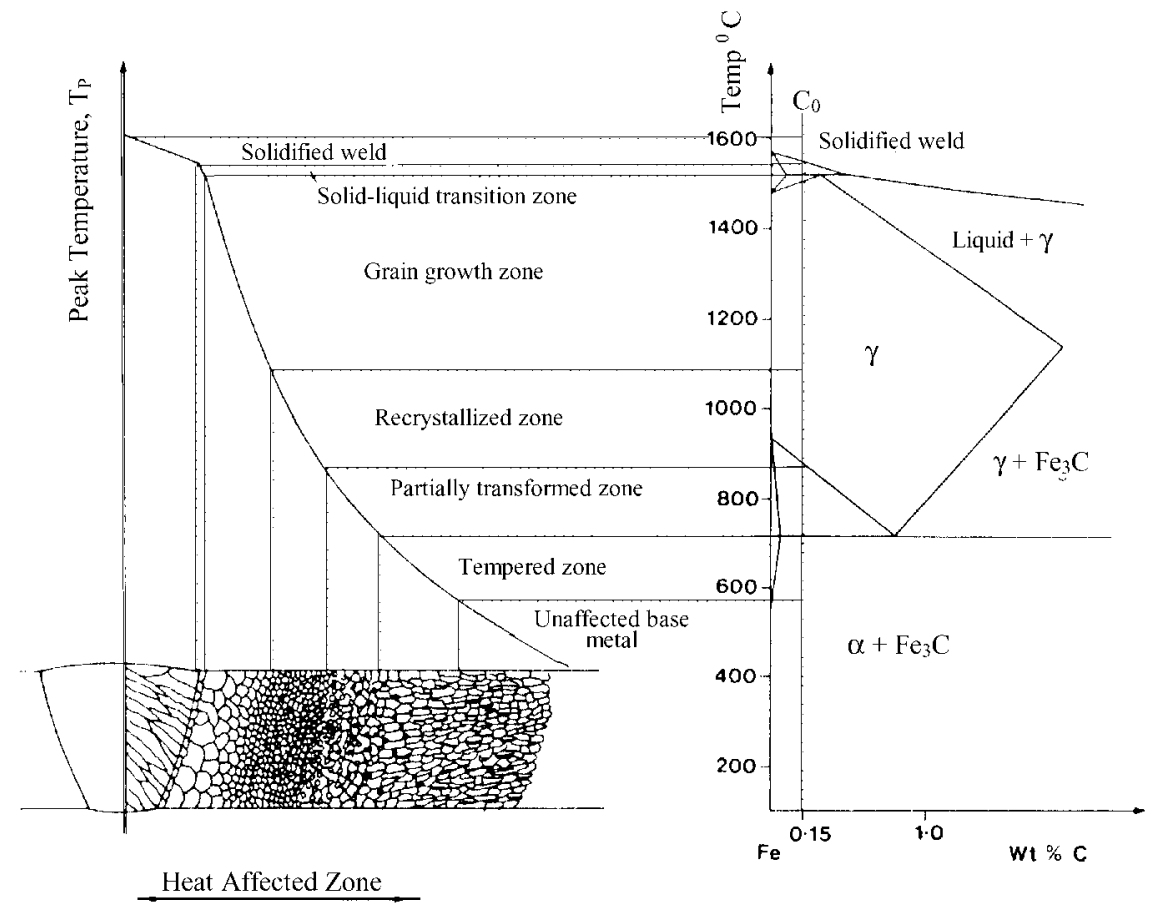

Fig. 4 A schematic diagram of the various subzones of the HAZ approximately corresponding to the alloy with $\mathrm{C}_{0}(0.15 \mathrm{wt} \% \mathrm{C})$ indicated on the $\mathrm{Fe}-\mathrm{Fe}_{3} \mathrm{C}$ equilibrium. (After Easterling [17])

it would apply a similar stress to the specimens, but for the 'during-welding' treatments the applied stress in this calibration would not apply to the real applied stresses. These would be different due to the localized softening of the parent metal during welding. Also the non-linear mechanical properties due to the change in temperature would cause further complication. However, the calibration is still valid, since it does ensure that a known degree of vibration is applied to each specimen.

\section{RESIDUAL STRESS MEASUREMENT}

The residual stresses were measured using a scanning $\mathrm{X}$-ray diffractometer (Proto iXRD). After calibrating the $\mathrm{X}$-ray diffractometer and determining the material elastic constant, the error band of the diffractometer itself was reduced to $\pm 10 \mathrm{MPa}$. This error band was used for 'postweld' treatments. However, for 'during-welding' treatments the error band was increased to $\pm 20 \mathrm{MPa}$ considering the fact that in 'during-welding' treatment process the residual stresses of different specimens were compared after treatment, where there was a possibility of material property difference from specimen to specimen although the specimens were prepared from the same bar. Contrarily, in the 'post-weld' treatment, the residual stress of the same specimen was compared before and after treatments, and so there was no possibility of material property difference.

In the X-ray measurement the single-exposure tech- nique was used, where a line map was measured on the selected line of the specimens (Fig. 2). The measurements were carried out using a fixed-position X-ray head, with the goniometer table moved to locate the measurement point under the head. The movement of the goniometer under the X-ray head was controlled by a computer. The specimens were located on the goniometer table using a positioning jig, with six point supports used to locate the specimens precisely in position each time. The specimens were levelled using a precision dial indicator. After positioning the specimens on the jig, they were clamped using a clamping screw, which prevented any movement of the specimens relative to the goniometer table and clamping jigs. Since the specimens were prepared from bright mild steel, there was not any scale on the surface. After completion of welding, the surface was cleaned using a soft tissue paper and then the residual stress measurement was carried out, i.e. no further surface treatment was carried out. The conditions of the X-ray measurements are shown in Table 3.

Table 3 X-ray measurement conditions

\begin{tabular}{ll}
\hline X-ray type & $\mathrm{Cr} \mathrm{K} \alpha$ \\
Diameter of the X-ray beam & $1 \mathrm{~mm}$ \\
Bragg angle & $156.1^{\circ}$ \\
Measurement angle $\beta$ & $30^{\circ}$ \\
Oscillation of $\beta$ angle & $0^{\circ}$ \\
Peak fit & Gaussian \\
Number of exposure & 2 \\
Error band in 'post-weld' treatment & $\pm 10 \mathrm{MPa}$ \\
Error band in 'during-welding' treatment & $\pm 20 \mathrm{MPa}$ \\
\hline
\end{tabular}




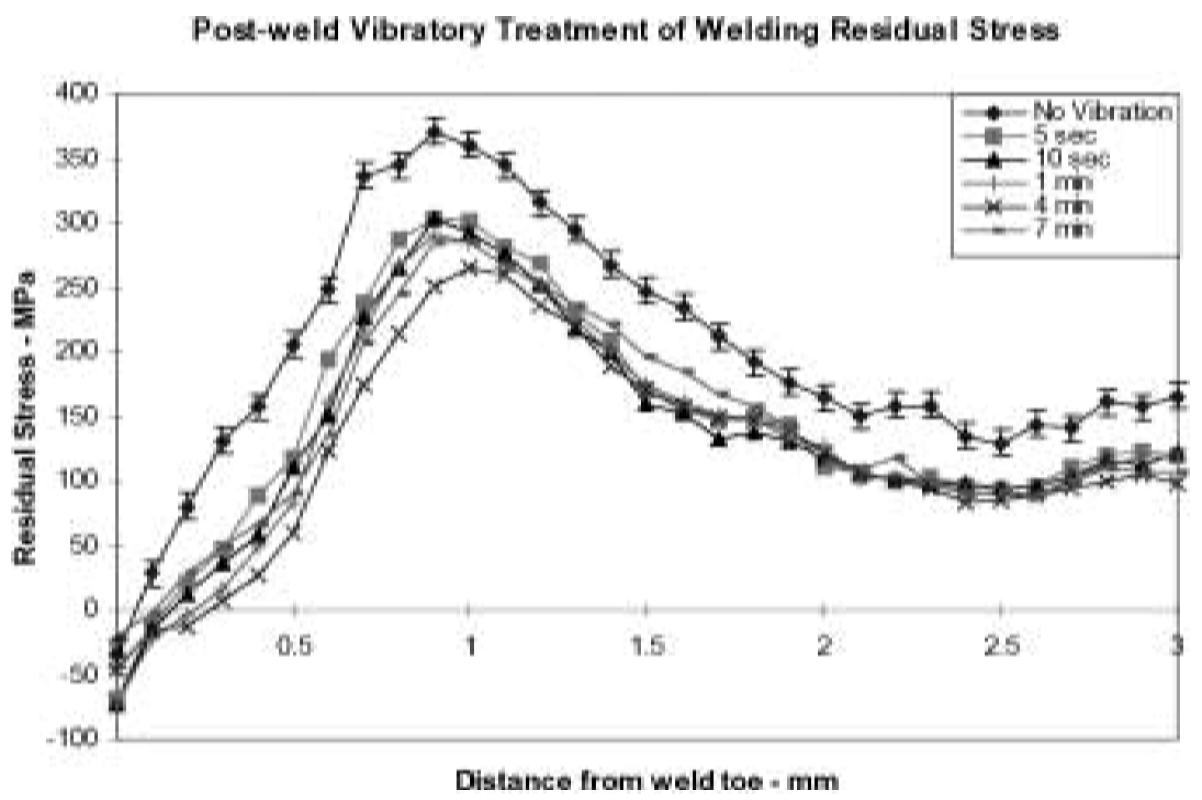

Fig. 5 Residual stress perpendicular to the weld line: sample 1

\section{EXPERIMENTAL RESULTS}

\subsection{Investigation of residual stresses}

\subsubsection{Results of the 'post-weld' treated specimens}

The plot shown in Fig. 5 is the result of a 'post-weld' treated specimen, in which the amplitude of vibration (hence the applied stress) was kept constant and the time of vibration was varied. From the result plot it will be seen that the residual stresses dropped by about $75 \mathrm{MPa}$ in the first $5 \mathrm{~s}$ of treatment over the entire measured line.
Further treatment intervals caused some change in the residual stress distribution but they were not so significant.

\subsubsection{Results of the 'during-welding' treated specimens}

The results of the 'during-welding' treatments are shown in Figs 6 and 7. The plots show that the residual stresses of the selected line (Fig. 2) of different specimens, where residual stresses of the control specimen and treated

\section{Longitudinal Residual Stresses}

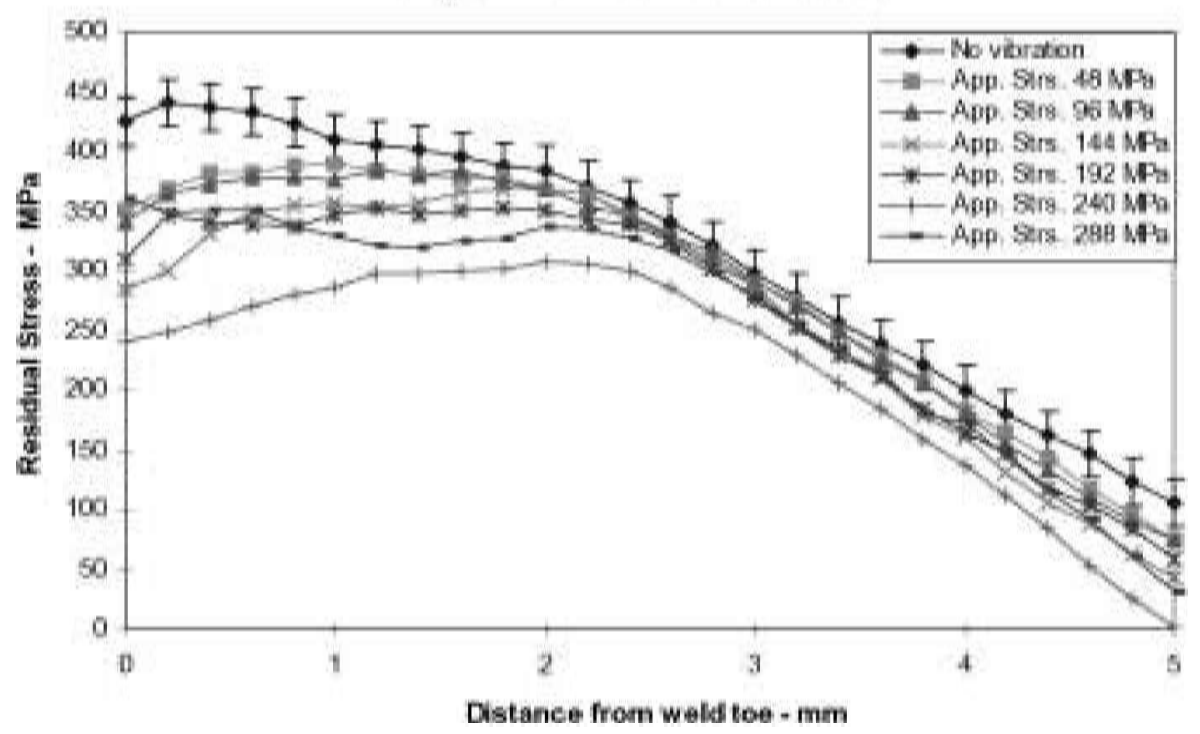

Fig. 6 Residual stress parallel to the weld line: sample 2 


\section{Transverse Residual Stresses}

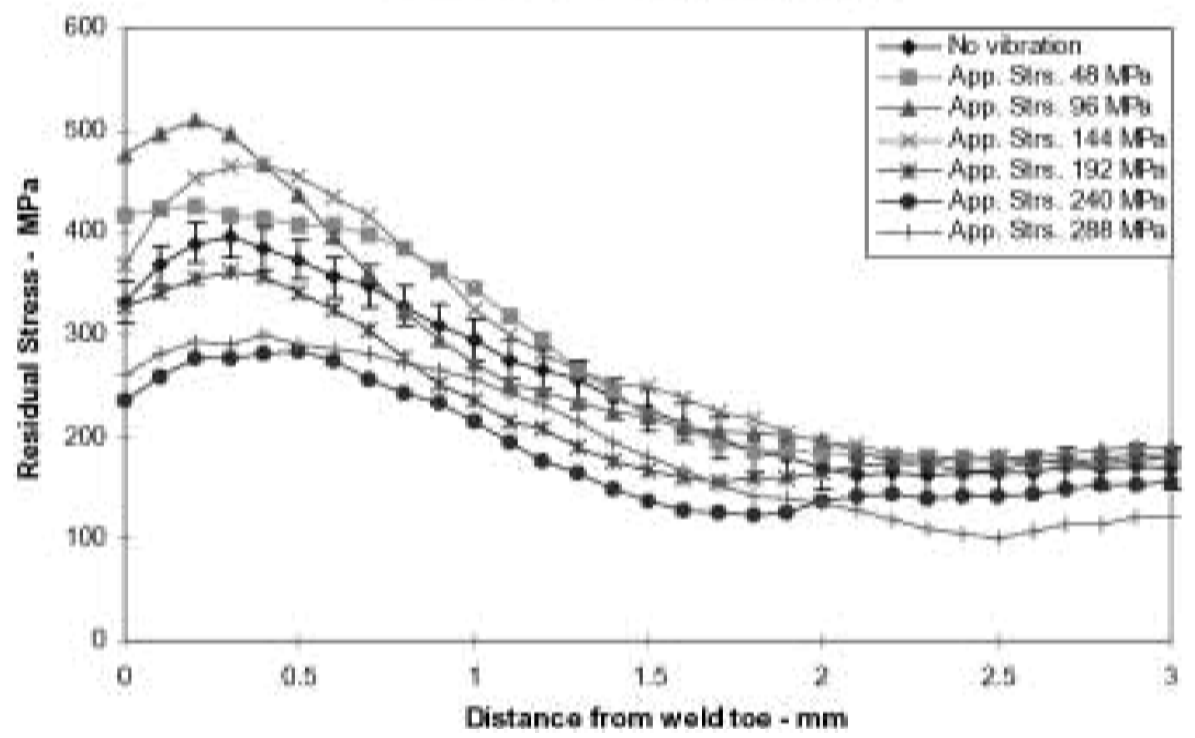

Fig. 7 Residual stress perpendicular to the weld line: sample 2

specimens are shown for ease of analysis. In the first plot (Fig. 6), the residual stresses parallel to the weld line are shown and, in the second plot (Fig. 7), the residual stresses perpendicular to the weld line are shown.

It will be seen from the plot that the residual stresses parallel to the weld line were found to decrease with the application of a low level of applied stress ( $\pm 48 \mathrm{MPa})$. With increase in the applied stress the residual stress was found to decrease further. However, beyond a certain level of applied stress the residual stress did not decrease further. The residual stresses perpendicular to the weld line were found to increase with the application of a low stress $( \pm 48 \mathrm{MPa})$ and were found to increase further with an increase in the applied stress. Beyond a certain level of applied stress $( \pm 192 \mathrm{MPa})$, a further decrease in the residual stress was observed.

\subsection{Crystallographic investigations}

\subsubsection{Investigation of 'post-weld' treated specimens}

Different sections of the weld and surrounding area of the 'post-weld' treated specimens were cut, polished and etched for this investigation. This found no difference between the microstructure of 'post-weld' treated specimens and untreated (control) specimens, in line with prior expectations.

\subsubsection{Investigation of 'during-welding' treated specimens}

Investigation of weld toe. Investigation was carried out in the weld toe (in the HAZ). The weld toe was polished and etched. In the welds of low heat input, the HAZ was small $(0.6-0.8 \mathrm{~mm})$. This made it difficult to observe the characteristics of the microstructure in detail. However, no significant difference between the microstructures of the vibrated and unvibrated (control) specimens was found. In the specimens of high heat input some differences between the microstructures of the HAZ were observed. However, they were not clear due to the small width $(0.35-0.5 \mathrm{~mm})$ of the grain growth zone.

Investigation in the side opposite the weld. The side opposite the weld of the plate was investigated. In low heat input welds there was no difference between the crystallographic structures of the vibrated and unvibrated specimens. However, an increase in the heat input in the specimens caused a significant difference. In the high heat input specimens, observation of the oxide bands showed that the peak temperature of the investigated area was between 1150 and $1300{ }^{\circ} \mathrm{C}$; i.e. the investigated area was in the grain growth zone (shown in Fig. 4). In this investigation, one specimen was welded without any vibration and six were vibrated applying three different amplitudes while the specimens were being welded (Table 4). For the unvibrated control specimen, five

Table 4 Applied stresses and time of vibrations to the specimens

\begin{tabular}{lll}
\hline $\begin{array}{l}\text { Number of specimens } \\
\text { processed }\end{array}$ & $\begin{array}{l}\text { Applied stress level } \\
(\mathrm{MPa})\end{array}$ & $\begin{array}{l}\text { Time of vibration } \\
(\mathrm{min})\end{array}$ \\
\hline 2 & \pm 75 & $2^{*}$ \\
2 & \pm 150 & $2^{*}$ \\
2 & \pm 224 & $2^{*}$ \\
\hline
\end{tabular}

* The time of vibration ( 2 min) includes $16 \mathrm{~s}$ of welding time. 
points in the half-width of the weld centre-line were investigated and these points are shown in Fig. 8. The microstructures of the five points of the control specimen are shown in Fig. 9.

For the applied stress amplitude of $\pm 75 \mathrm{MPa}$, no differences in the microstructures were observed; at the stress amplitude of $\pm 150 \mathrm{MPa}$, some small differences were found. At the stress amplitude of $\pm 224 \mathrm{MPa}$, the differences were quite perceptible. At this stress level, two specimens were processed and in both specimens a similar result was found. For this, both specimens were investigated choosing seven points in the half-width in the side opposite the weld line (Fig. 10). The microstructures of one of the two specimens processed with the applied stress of $\pm 224 \mathrm{MPa}$ are shown in Fig. 11 .

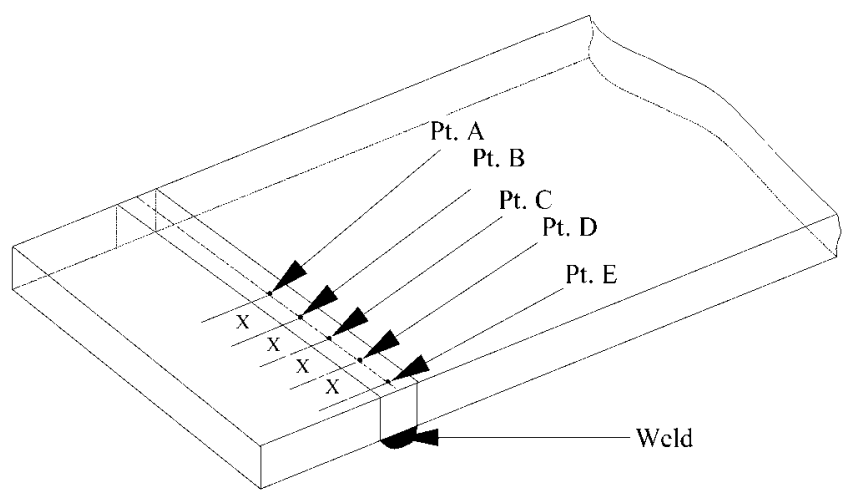

Fig. 8 Location of investigated area opposite the weld $(x=7 \mathrm{~mm})$

\section{Microstructures of the Control Specimens}
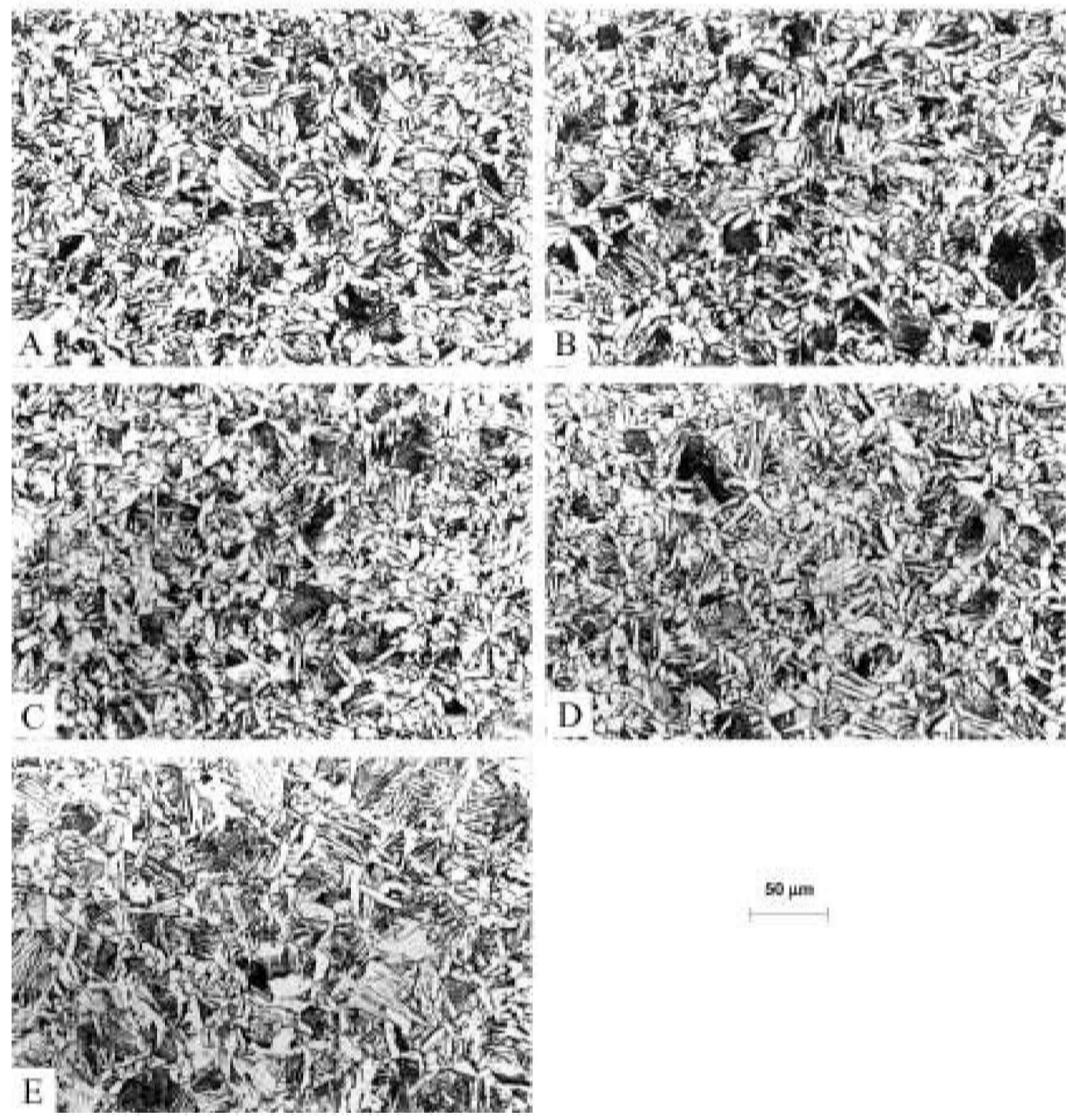

50 माт

Fig. 9 Observation points (A, B, C, D and E of Fig. 8) of the control specimen 


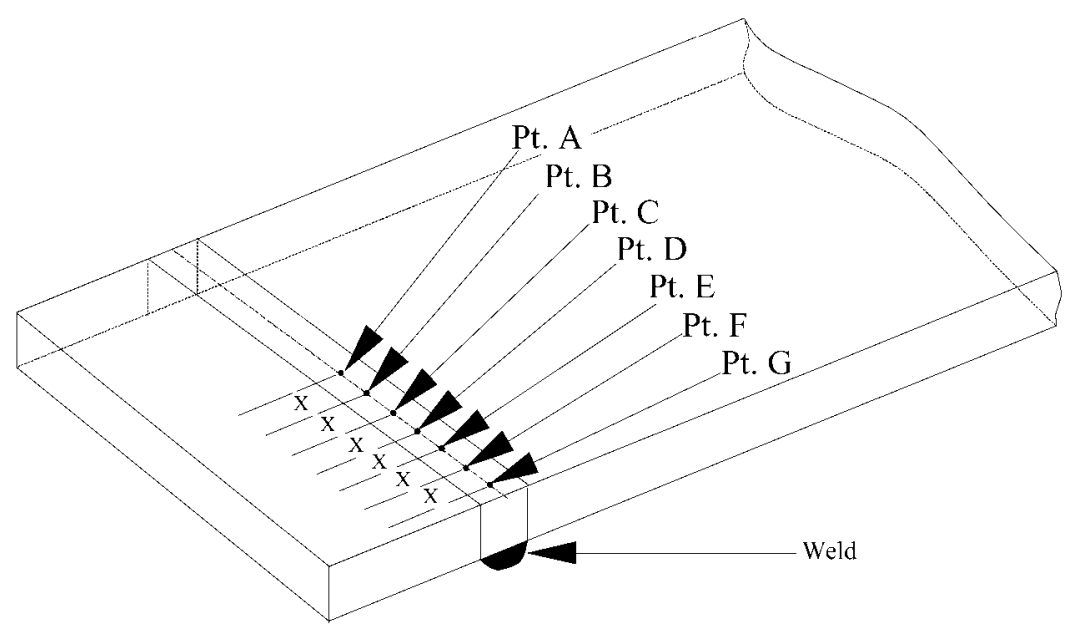

The microstructures of the control specimen (Fig. 9) were compared with the microstructures of the specimens vibrated at an applied stress of $\pm 224 \mathrm{MPa}$ (Fig. 11). The microstructures of the unvibrated specimen were found to be isotropic, with no particular arrangement of the crystal structure. The vibrated specimens showed a completely different picture in that the crystals were found to be arranged according to the direction of the applied stresses. The ferrite crystals were found to form at approximately $\pm 45^{\circ}$ to the direction of the applied stresses (see, in particular, points $\mathrm{C}, \mathrm{D}, \mathrm{E}$ and $\mathrm{F}$ of Fig. 11). The orientations of the crystals were found to be position dependent in the specimen. At the midwidth there was a very small or negligible orientation of the crystals but towards the edge of the specimen the orientation increased and again very near to the edge the orientation was found to be very small. Figure 12 explains the trend of the crystal structure arrangements.

Investigation in the weld microstructure. The weld top surface was polished and etched. The control specimen was compared with specimens subjected to an applied stress of $\pm 224 \mathrm{MPa}$. The crystal structures of the weld top of the control specimens showed a random pattern structure with no particular trend of arrangement of the crystal structures. In the specimens vibrated at stress amplitude of $\pm 224 \mathrm{MPa}$, some pattern arrangement of the crystal structures was observed. Ferrite crystals were found to be aligned according to the directions of the applied stress. However, this pattern was not particularly evident.

Investigation in the sectioned weld. The welds were sectioned for observation (Fig. 13). The section faces were polished and etched. On the section face, three points were observed, details of which are shown in Fig. 14.
For points A and B of Fig. 14, the vibrated specimens showed the approximately $\pm 45^{\circ}$ alignment pattern of the crystal structures. Point A of Fig. 14 showed a more clearly defined cross pattern than that of point $\mathrm{B}$. The ferrite crystal cross patterns were found to form at approximately $\pm 45^{\circ}$ to the direction of the applied stresses. Near the weld toe (point $\mathrm{C}$ in Fig. 14), no particular orientation was found. The ferrite grains at the observed points (points A, B and C) of the control specimens were in a random pattern, with no particular orientation.

Comparison of crystal size. For comparison of the size of the crystals, point A (of Fig. 14) of a welded section was magnified similar to that of the magnification of the as-received flat bar of Fig. 1. In the vibrated sample (Fig. 15) the grain sizes were found to be refined and aligned approximately $\pm 45^{\circ}$ to the applied stress due to the vibratory stresses.

\subsection{Investigation of hardness of the specimens}

The hardnesses of the control specimens and specimens subjected to vibration were measured. Two groups of specimens were tested. In the first group, a total of four points were measured (points A, B, C and D of Fig. 8). In the second group, all five points (A, B, C, D and E) of Fig. 8 were measured. The hardnesses of the two groups are shown in Tables 5 and 6 .

In the first group the specimens subjected to an applied stress of $\pm 150 \mathrm{MPa}$ showed similar hardnesses to the hardnesses of the control specimens. With increase in the applied stress to $\pm 224 \mathrm{MPa}$, the hardnesses of the metal increased by up to 19 per cent. In the second group the applied stress was $\pm 224 \mathrm{MPa}$, and the hardnesses were found to increase by up to 25 per cent in comparison with those of the control specimens. 


\section{Mierostructures of Specimen 1 (Induced Stress $\pm 224 \mathrm{MPa}$ )}
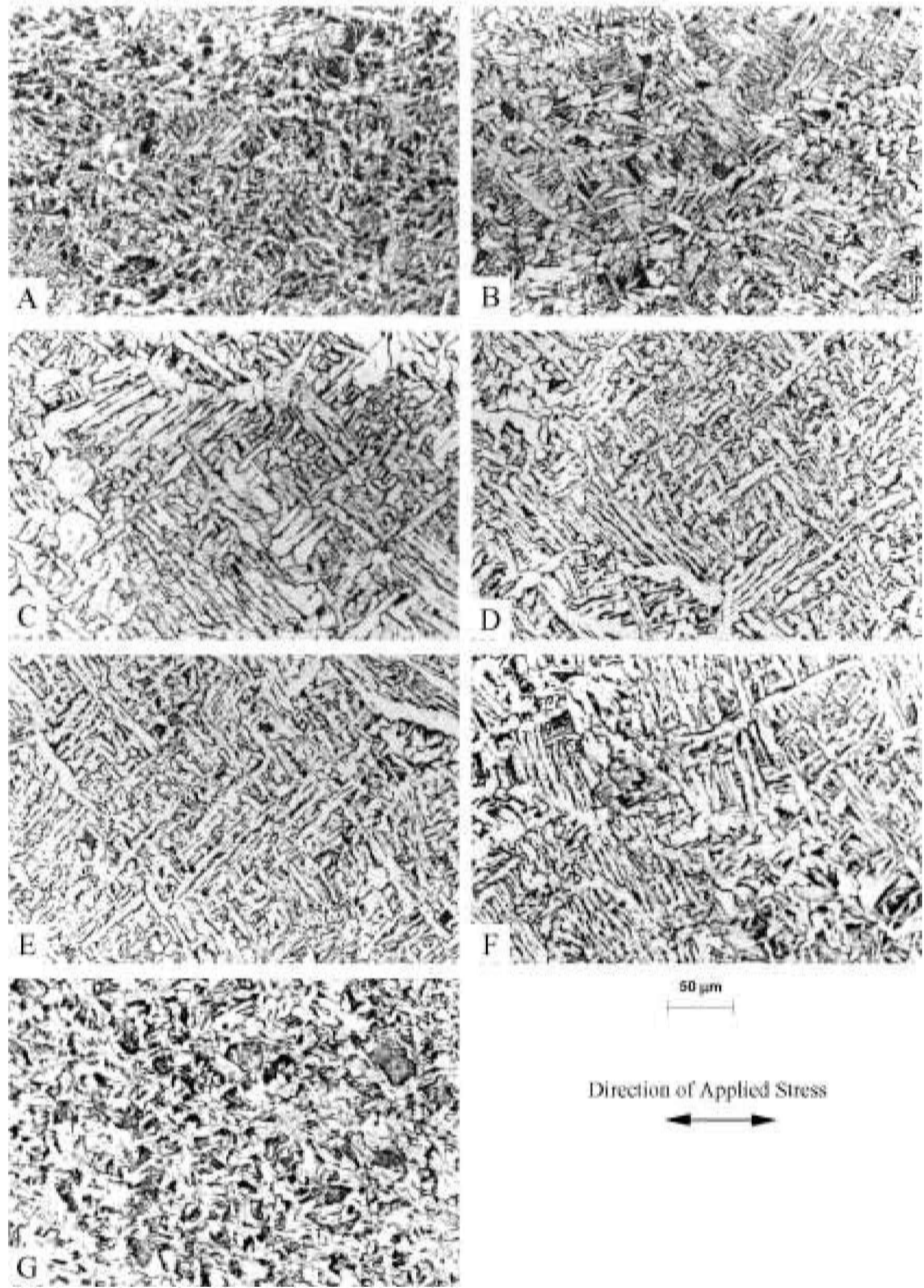

Eit um

Ditection of Applied Siress

Fig. 11 Microstructures of the vibrated specimens (points A, B, C, D, E, F and G of Fig. 10) 


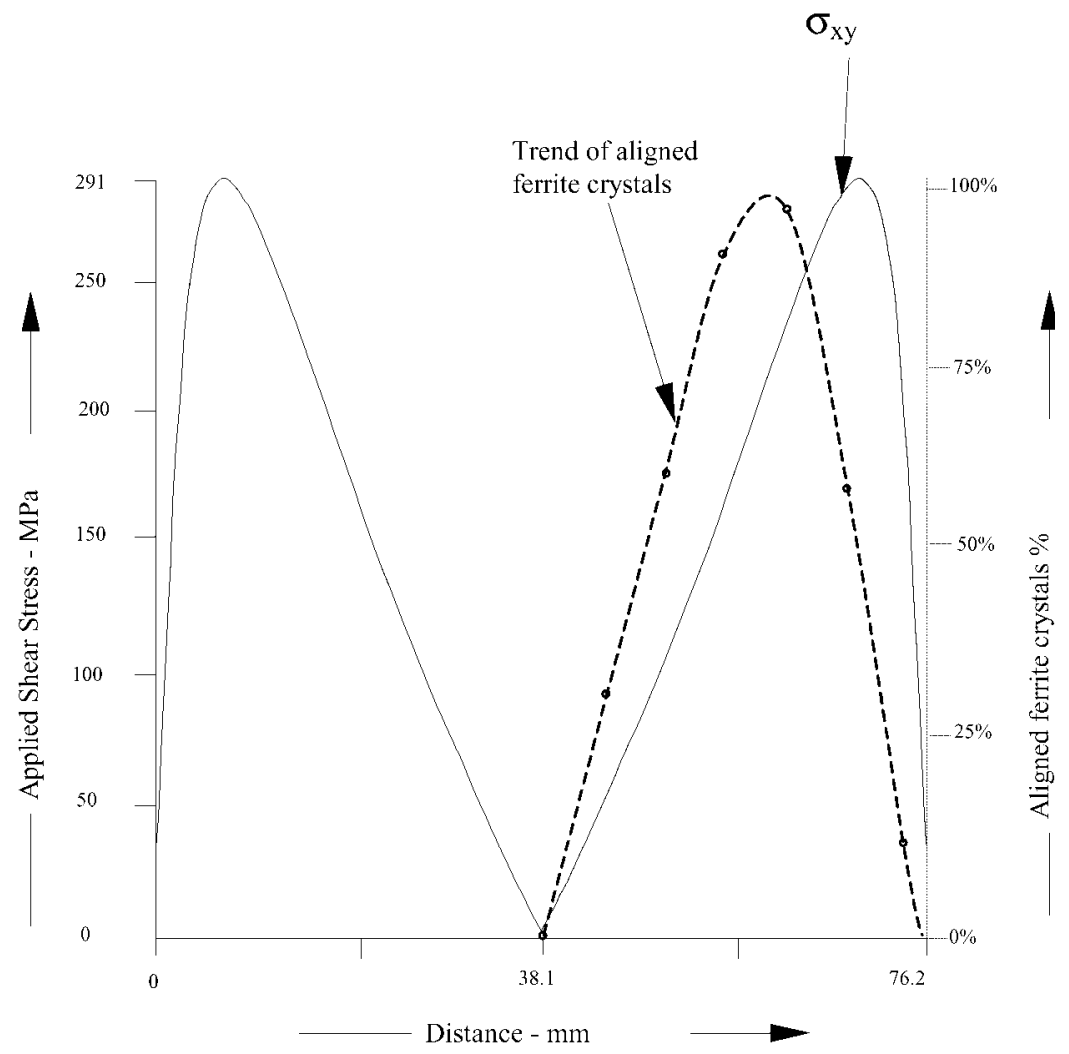

Fig. 12 Applied shear stresses on the side opposite the weld (reproduced from a finite element software ANSYS plot) and percentage of ferrite crystals oriented approximately $\pm 45^{\circ}$ to the applied stress axis

\section{DISCUSSION OF RESULTS}

In the 'post-weld' treatment, the residual stresses perpendicular to the weld line were measured. The stress levels were found to decrease by about $75 \mathrm{MPa}$ in the first $5 \mathrm{~s}$ of vibration. An increase in the vibration time did not show any further decrease in residual stress. The metallurgical investigation of the 'post-weld' treated specimens showed no difference between the microstructures of the control specimens and the microstructure of 'postweld' treated specimens. This implies that 'post-weld' vibratory treatment does not result in any microstructural difference, which is visible in optical microscopy (as could be anticipated).

The residual stresses parallel and perpendicular to the weld line of the 'during-welding' treated specimens were

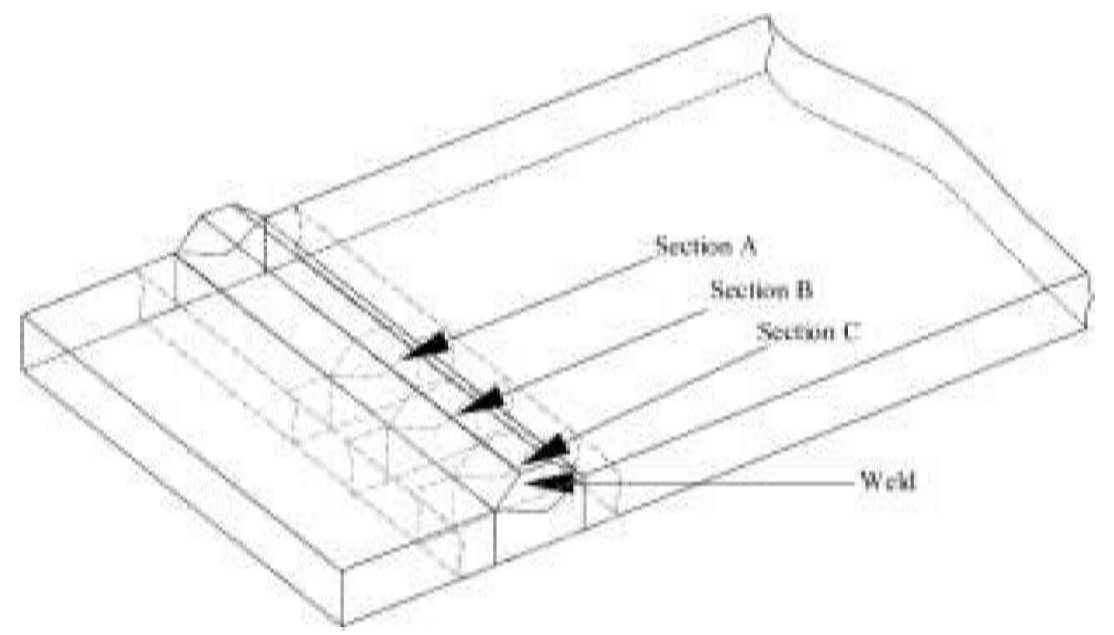

Fig. 13 Position of the sectioned area under investigation 


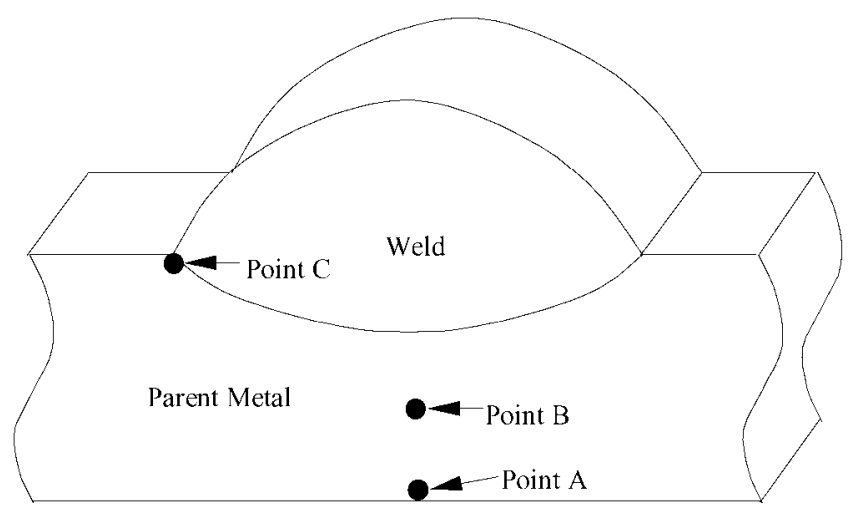

Fig. 14 Position of the investigated area of the weld sections

measured. The residual stresses parallel to the weld line were found to decrease at low levels of applied stresses. An increase in the applied stress caused a further decrease but to a lesser degree. The residual stresses perpendicular to the weld line were found to increase with application of a small and medium range of applied stresses but after a certain level of applied stress the residual stresses were found to decrease. The metallurgical investigation of the specimens of low heat input showed no observable difference in the microstructures. The samples of high heat input showed cross patterns of the ferrite crystal structures in the direction at approximately $\pm 45^{\circ}$ to the stress axis. This result shows agreement with the work of Bhadeshia [15], who applied a uniaxial static stress to the specimens and found anisotropy in the crystal structures. It may be concluded that, like the static stress used in Bhadeshia's work, the dynamic applied stresses have a similar effect on the transformation products of austenite.

This orientation of the change in the crystal structure appears to be related to the dynamic applied shear stress characteristics of the specimens. The dynamic stress applied to the specimens was determined by a finite element analysis (Fig. 12). It was found that the distribution of the dynamic shear stresses in the specimens was similar to the trend of the crystal orientation found in this investigation. The similarity of the curves in

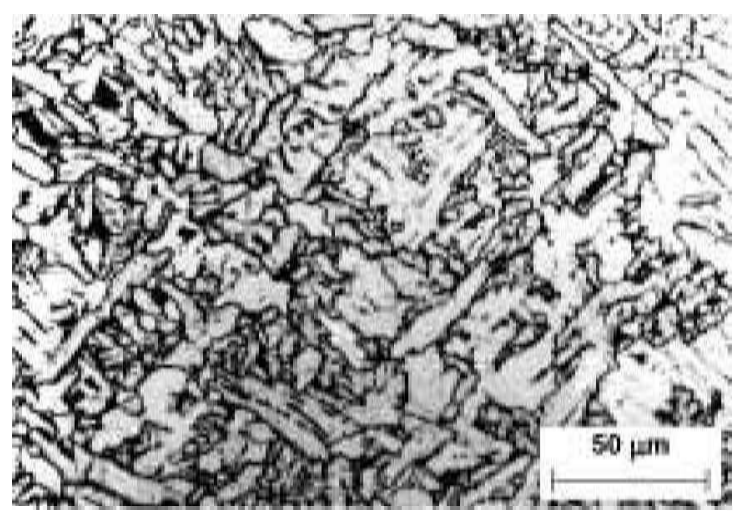

Fig. 15 Microstructure of point A of Fig. 14
Table 5 Vickers hardnesses of vibrated and control specimens (first group)

\begin{tabular}{|c|c|c|c|c|}
\hline \multirow[b]{2}{*}{$\begin{array}{l}\text { Measurement } \\
\text { point }\end{array}$} & \multicolumn{3}{|c|}{ Vickers hardness* } & \multirow{2}{*}{$\begin{array}{l}\text { Maximum } \\
\text { increase in } \\
\text { hardness } \\
(\%)\end{array}$} \\
\hline & $\begin{array}{l}\text { Control } \\
\text { specimen }\end{array}$ & $\begin{array}{l}\text { Applied } \\
\text { stress } \\
\pm 150 \mathrm{MPa}\end{array}$ & $\begin{array}{l}\text { Applied } \\
\text { stress } \\
\pm 224 \mathrm{MPa}\end{array}$ & \\
\hline A & 177.4 & 158.7 & 180.6 & 2 \\
\hline B & 161.5 & 162.6 & 188.7 & 17 \\
\hline $\mathrm{C}$ & 165.4 & 159.3 & 190.8 & 15 \\
\hline D & 158.7 & 159.8 & 189.4 & 19 \\
\hline
\end{tabular}

* The error band of the Vickers hardness numbers is \pm 2 .

Table 6 Vickers hardnesses of the vibrated and control specimens (second group)

\begin{tabular}{llll}
\hline & \multicolumn{2}{c}{ Vickers hardness } & \\
\cline { 2 - 3 } $\begin{array}{l}\text { Measurement } \\
\text { point }\end{array}$ & $\begin{array}{l}\text { Control } \\
\text { specimen }\end{array}$ & $\begin{array}{l}\text { Applied stress } \\
\pm 224 \mathrm{MPa}\end{array}$ & $\begin{array}{l}\text { Maximum increase } \\
\text { in hardness (\%) }\end{array}$ \\
\hline A & 159.8 & 185.9 & 16 \\
B & 160.4 & 188 & 17 \\
C & 158.7 & 193.6 & 22 \\
D & 161.5 & 194.4 & 20 \\
E & 165.9 & 208.1 & 25 \\
\hline
\end{tabular}

Fig. 12 tend to indicate that the change in structure is related to the applied shear stress.

The orientations of the crystals of the specimens were observed from two perpendicular planes of the weld (Figs 10 and 14), and from both observation planes the orientation of the ferrite crystals was seen to be at approximately $\pm 45^{\circ}$ to the stress axis. This implies that the orientation was not simply $45^{\circ}$ to the stress axis. This angle may be determined from the cube shown in Fig. 16, where the crystals are seen to be aligned at $45^{\circ}$ to the

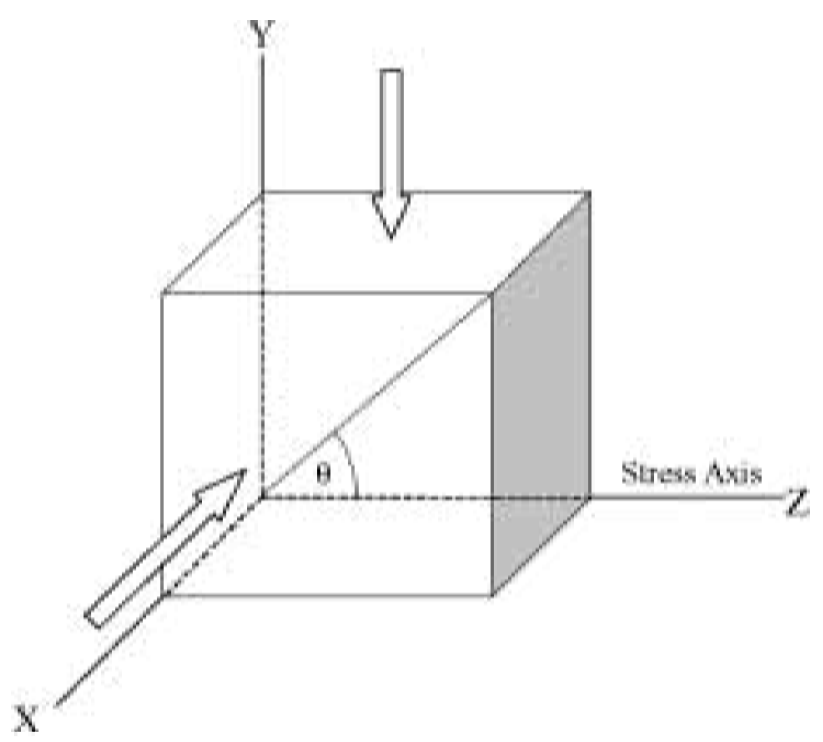

Fig. 16 Viewing direction of the crystal orientations 
Increase in the Hardness due to Application of Dynamic Stress

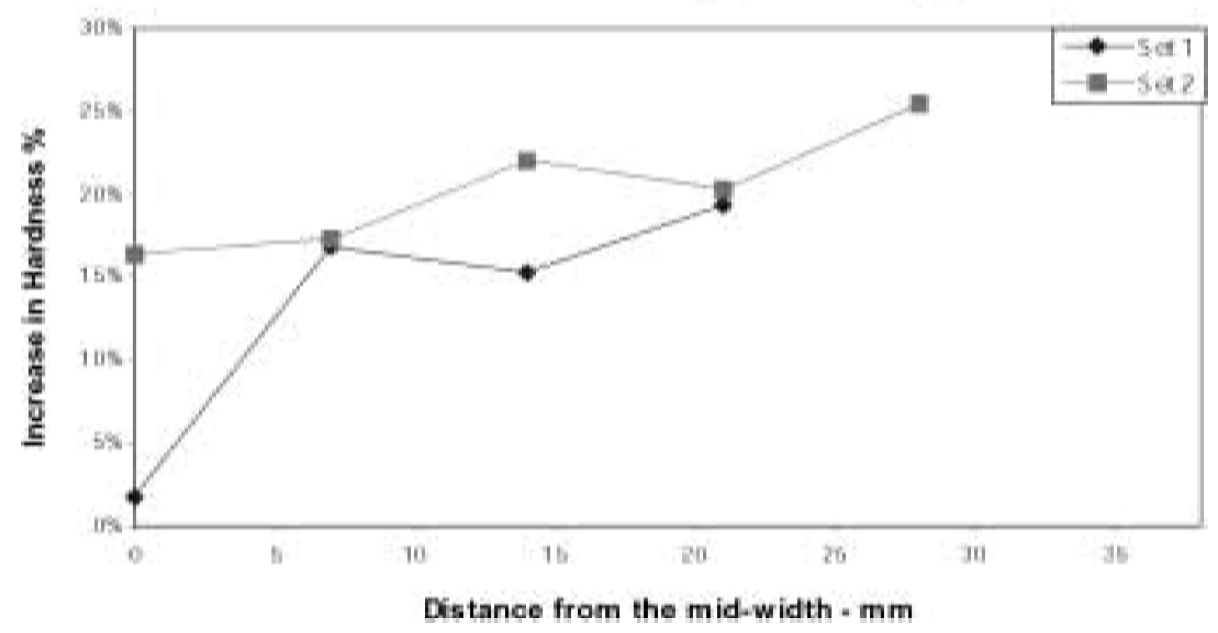

Fig. 17 Increase in the hardness of the metal at different positions of the plate

stress axis on two perpendicular planes. This can only happen if the crystals are aligned along the diagonal of the cube. If the observation axes are $X$ and $Y$ and the force axis is $Z$, then the orientation angle with the stress axis is $\theta=55^{\circ}$ (Fig. 16).

The high amplitude of vibration (applied stress of $\pm 224 \mathrm{MPa}$ ) caused an increase in hardness with a maximum of 25 per cent. This result agrees with the findings by Campbell [16], who looked at the metallurgical properties of castings after vibration. The hardness increased as the distance of the observation point increased from the mid-width. This trend is similar to the trend of the crystal orientation due to the applied stress during welding (Fig. 12). The hardnesses of the two sets of the measurements are plotted in Fig. 17, where it can be seen that, as the distance of the observation point from the mid-width increased, the hardness of the steel also increased.

Grain refinement occurred in the high-heat and highamplitude vibrated specimens, which is in agreement with the work of Campbell [16], where it was established that grain refinement causes an improvement in mechanical properties. This investigation suggests that crystal orientation may be also another cause of the improvement in the mechanical properties.

\section{CONCLUSIONS}

From this investigation the following conclusions were made:

1. 'Post-weld' vibratory treatment does not make any significant difference in the crystal structures as far as optical microscopy is concerned.

2. 'During-welding' vibratory treatment causes the crys- tals to grow in a pre-defined direction which is at approximately $55^{\circ}$ to the stress axis. In lower applied stresses no difference could be observed by optical microscopy.

3. Grain refinement occurs and hardness increases in the high-amplitude vibrated specimens. The increase in hardness seems related to the orientation of the crystals.

\section{REFERENCES}

1 Tewari, S. P. and Shanker, A. Effect of longitudinal vibration on the mechanical properties of mild steel weldments. Proc. Instn Mech. Engrs, Part B, Journal of Engineering Manufacture, 1993, 207(B3), 173-177.

2 Munsi, A. S. M. Y. Investigation and validation of vibratory methods for stress relieving and weld conditioning. $\mathrm{PhD}$ thesis, University of Strathclyde, Glasgow, February 1999.

3 Aoki, S. and Nishimura, T. Analytical model improvement of residual stress of welding joint using vibration. In Proceedings of the 1995 Joint ASME-JSME Pressure Vessels and Piping Conference, Honolulu, Hawaii, 23-27 July 1995, Current Topics in Computational Mechanics, 1995, PVP-Vol. 305, pp. 75-79 (American Society of Mechanical Engineers, New York).

4 Aoki, S., Nisimura, T., Hiroi, T. and Amano, Y. Reduction of residual stress of welded joint using vibration. Nippon Kikai Gakkai Ronbunshu C (Trans. Japan Soc. Mech. Engrs C), 1995, 61(592), 4800-4804.

5 Maekawa, Y., Nakagiri, A. and Maeda, H. The behaviour of surface residual stress relief and lattice defect density with mechanical vibration in FC 25 cast iron. Nippon Kikai Gakkai Ronbunshu A, 1986, 52(477), 1295-1299.

6 Nakagiri, A., Maeda, H. and Kita, M. The behaviour of vibrational surface residual stress relief in FC 25 cast iron. 
Nippon Kikai Gakkai Ronbunshu A, 1984, 50(452), 751757.

7 Bühler, H. and Pfalzgraf, H. G. Investigation into the reduction of residual welding stresses by alternating stress tests or mechanical vibration. Schweisse Schreiden, 1964, 16(5), 178-184.

8 Shanker, S., Wood, W. E. and Khan, K. H. Effect of vibratory stress relief treatments on residual stress in mild steel butt welds. In Proceedings of the 12th National SAMPE Technical Conference, 7-9 October 1980, pp. 776-786.

9 Sonsino, S. M., Müller, F., deBack, J. and Gresnigt, A. M. Influence of stress relieving by vibration on the fatigue behaviour of welded joints in comparison to post-weld heat treatment. Fatigue Fracture Engng Mater. Structs, 1996, 19(6), 703-708.

10 Wozney, G. P. and Crawmer, G. R. An investigation of vibration stress relief in steel. Weld. Res. Suppl., 1968, 23(9), 411-419.
11 Houck, F. Putting vibration to work. Mech. Engng, 1966, 88(9), 48-50.

12 Botros, B. M. Residual stresses in welded steel structure. II. SME technical paper MF80-305, 1980.

13 Rich, S. R. Quantitative measurement of vibratory stress relief. Weld. Engr, 1969, 54(3), 44-45.

14 Fenghua, S. and Dexin, F. Tests of residual stress on welded structure under vibratory stress relief. J. Dalian Univ. Technol., August 1994, 34(4), 390-393.

15 Bhadeshia, H. K. D. H. Possible effects of stress on steel weld microstructure. In Mathematical Modelling of Weld Phenomena., Vol. 2, 1995, pp. 71-118 (Institute of Materials, London).

16 Campbell, J. Effect of vibration during solidification. Int. Metals Rev., 1981, 26(2), 71-108.

17 Easterling, K. Introduction to the Physical Metallurgy of Welding, 1992 (Butterworth-Heinemann, Oxford). 